\title{
Architectural design in accordance with fire requirements for condominiums in Vietnam
}

\author{
Pham Trong Thuat ${ }^{1, *}$ \\ ${ }^{1}$ Hanoi Architectural University, Vietnam.
}

\begin{abstract}
Development of condominium is unavoidable by developing urban area, in order to utilize the infrastructure within a limited surface area, as an addition to the number of housing, targeting residents with average and below average income. Large cities in Vietnam such as Hanoi, Ho Chi Minh City, Danang etc. have been able to develop similar condominium buildings in order to provide shelter to the residents mentioned above. Projects of condominium buildings have been able to solve the need of shelter for many urban, as well as authorized organization by the government would have more options of changing the appearance of the developing cities, heading towards the model of other developed cities in the world. In the last decade, in large and developing cities, a large number of condominium have been built with improving quality and design over time. However, the minimum requirements of general infrastructure in case of fire emergency are not met by some buildings. The number of fire incidents in buildings like these is increasing due to a various numbers of reasons, including lack of precautions in the designing phase of the buildings.
\end{abstract}

\section{Situation and cause of fire incidents in condominiums}

\subsection{Situation}

According to the latest data, there are 718 condominiums in Hanoi and nearly 1000 in Ho Chi Minh City. However, the investors, the deploying unit, residents and the responsible individuals' attitude towards fire precautions are relatively poor. To be specific, only 179 out of 718 buildings in Hanoi have purchased fire insurance; and in the 4 years' period of 2012-2016, there were 34 fire incidents in high-rise building, 26 of those are condominiums (average of 7 per year). Due to the fact that there is an increasing number of fire incidents on this particular type of building in developing cities, causing several casualties and damage properties, installing fire precautions should really be a major consideration for the government of local cities, investors, landlords and residents.

In order to limit the negative impacts in fire incidents, precautions in architectural designing phase is considered to be vital. These precautions in design help to increase the chance of surviving and/or escaping in case of a fire emergency for residents in these

\footnotetext{
Corresponding author: thuatarch@yahoo.com
} 
condominiums. By doing this, the architecture will predict what would happen in a fire incident and come up with solutions in design such as possible pathways for residents to escape in case of a fire emergency. Also by doing this, the spread of fire and smoke can also have limited from area that has a high chance of getting caught in the fire, and designing so that it would be easier to fire departments and law enforcement in saving people and extinguishing the fire.

\subsection{Cause of fire incidents}

Condominiums are buildings with high concentration of people. Residents of these buildings are varying, with different attitude and knowledge of fire causation, many with limited knowledge and attitude towards fire causation. However, the designing process is also a main reason of increasing the risk of getting a fire incident in condominiums. These layouts designing include as follows:

- The layout of the building has not met the requirement for fire department vehicles to operate outside the building.

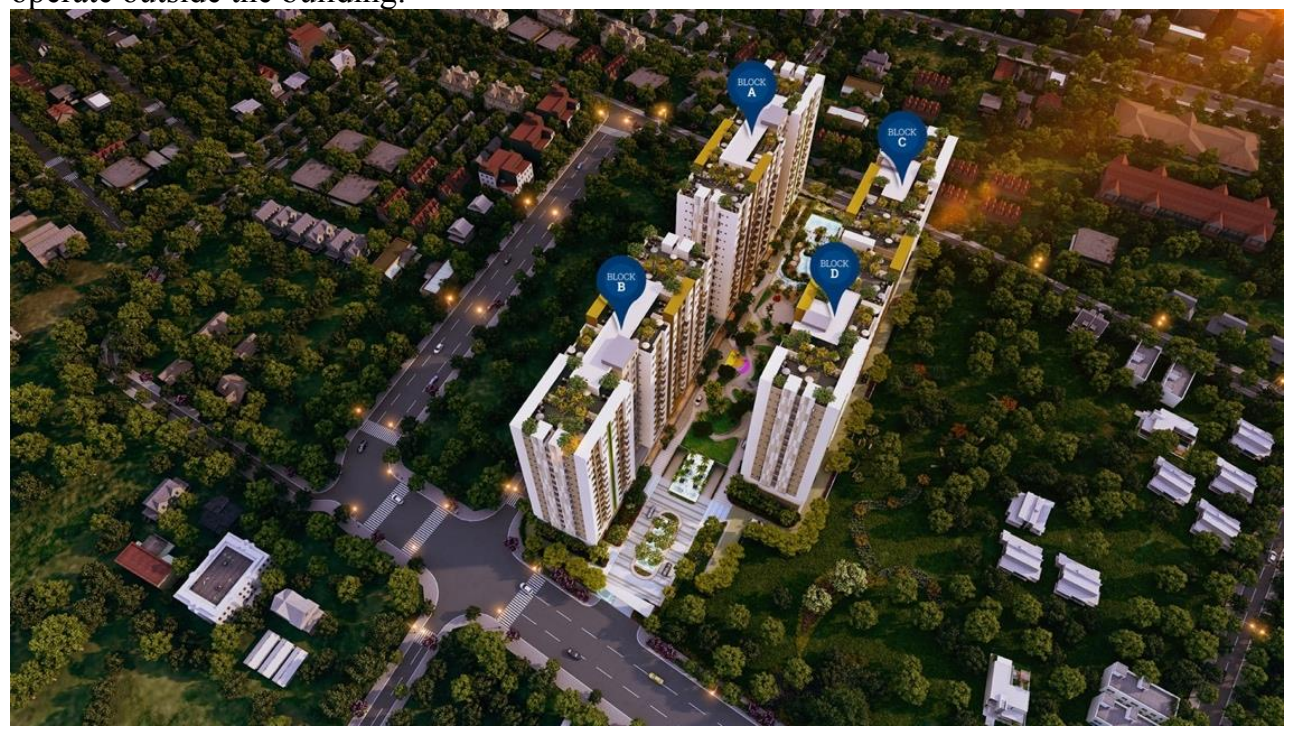

Fig. 1. Overall layout cannot be approaches by fire trucks.

- In the case of fire, gasses, smoke and fire are tended to spread vertically, which is a main reason that leads to fire in a larger area. As the height increases, the speed and pressure of the air increase, spreading the fire even faster. These two elements depend on the convectional structure of the building, the direction of the wind and the surrounding area.

- The fire exits are the stairs (vertical traffic) so that the movement is likely to be much slower than that of horizontally, resulting in longer escaping from time.

- The architecture did not design for vents for smoke in case of a fire emergency.

- The greater the height, the harder it gets for the fire department to extinguish the fire, especially with buildings that has extreme height, when the reach of the ladder on the fire truck is limited.

- The legal requirements of fire procedures and layouts are still lack of information. The designing consultants usually have to design based on different standards, especially mixed buildings of shopping center, department stores, offices and apartments. The share of elevator, stairs and lobby is also one of the reason leads to the risk of a fire incident. 
- In order to utilize the cost, some condominiums have long and narrow hallway, resulting in lack of time to reach to the emergency exit. Some buildings have too many rooms on one single level, leading to a large number of people in need of escaping in the fire incident.

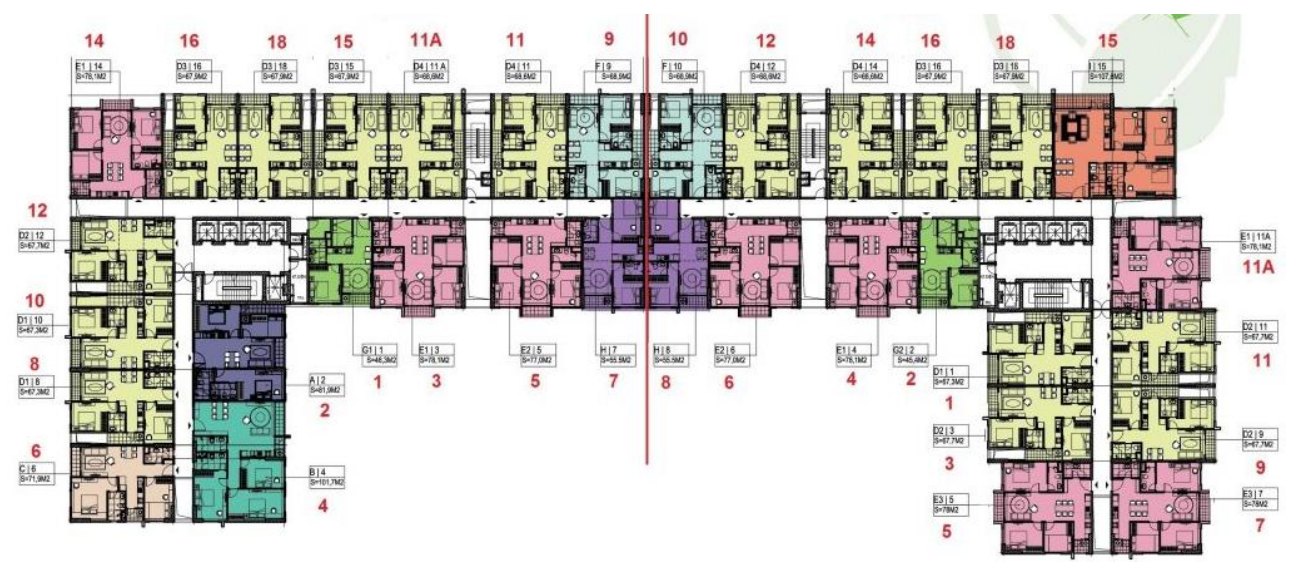

Fig. 2. Long and narrow hallway, large number of apartments on one single floor - difficulties in providing an emergency exit.

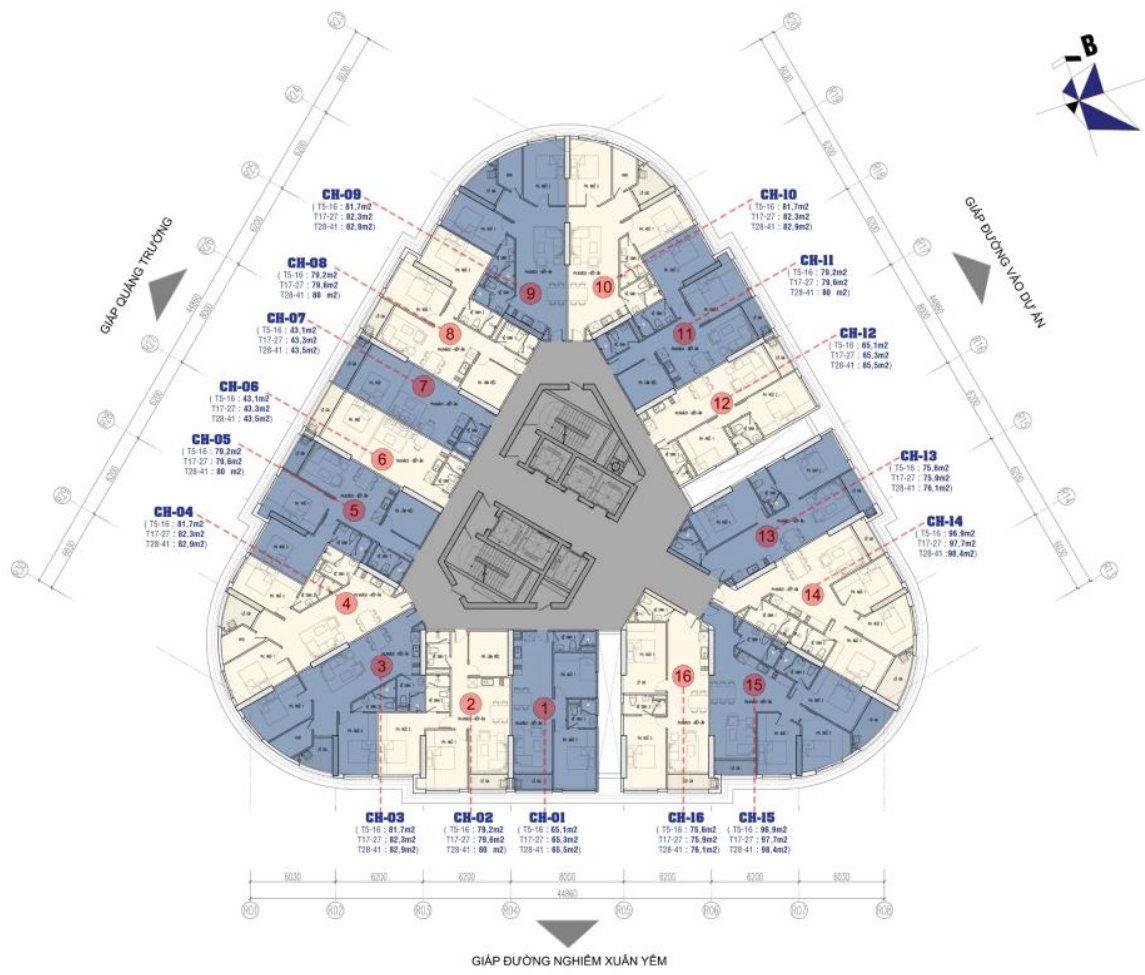

Fig 3. The fire exit is surrounded, the fire enforcement will not be able to help in case of a fire

- Does not meet the required numbers of stairs. To utilize the cost, many buildings have their apartments stacked around a single stair, resulting in the lack of clean air and the accessible to the fire enforcement. 
- Low-quality materials that do not meet the fire precautions requirement or materials that are not suitable for condominiums is also one of the reasons that leads to a fire.

\section{Design solutions}

\subsection{Formation and location:}

- General planning so that the building is accessible for the fire departments and fire trucks, including: pathway for fire trucks, the width and length of the pathway, minimum turning radius.

- Calculations of wind directions, formation of surrounding buildings is also needed to be considered.

- For condominiums built in area that does not allow the above conditions, fire hydrants and water tanks are needed to be in prioritized position in front of the building.

- The condominiums' infrastructure must meet the same requirements to the surrounding buildings. For example, two buildings that can withstand fire of level I, II needed to be at least 6 meters away from each other.

\subsection{Designing solutions}

\subsubsection{Typical floor layout}

- In order to increase the chance of escaping in a fire, the layout of a condominium needs to be clear in traffic and the emergency stairs are accessible. Therefore, the maximum distance between the furthest point to the emergency exit needs to be met.

- Other than utilize the space for horizontal traffic on a floor, the stair's M1, M2, M3 are also needed to meet the safety precaution requirements.

- Ventilation requirements and lighting in the lobby and hallways are also required. However, the spread of smoke and fire also needs to be premeditated. Emergency stairs are also needed to be in prioritized locations.

- In designing the apartments, kitchens should be located in the sides of the apartment, and they should not be next to the entrance of the apartment, as it would block the escape of the resident, and also forming a potential concentrated area of fire, make it easier to spread horizontally.
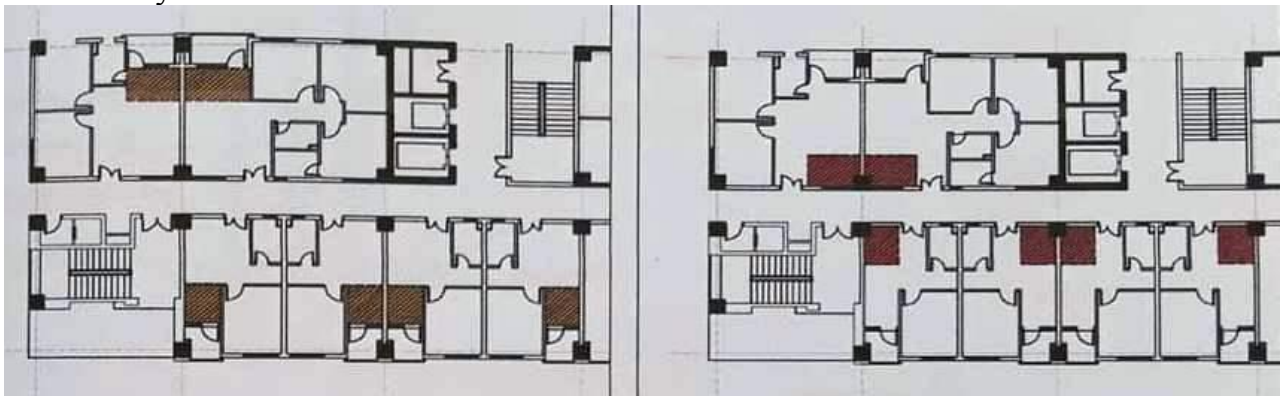

Fig 4. Kitchens location: for and againsnt 


\subsubsection{Organizing functional area}

- Functional area are needed so that the resident has shelter while waiting for the fire enforcement. Specifically, buildings with height greater than 28 meters need a single floor with different air pressure and safety precautions both vertically and horizontally. The entrance also requires fire-proof material.

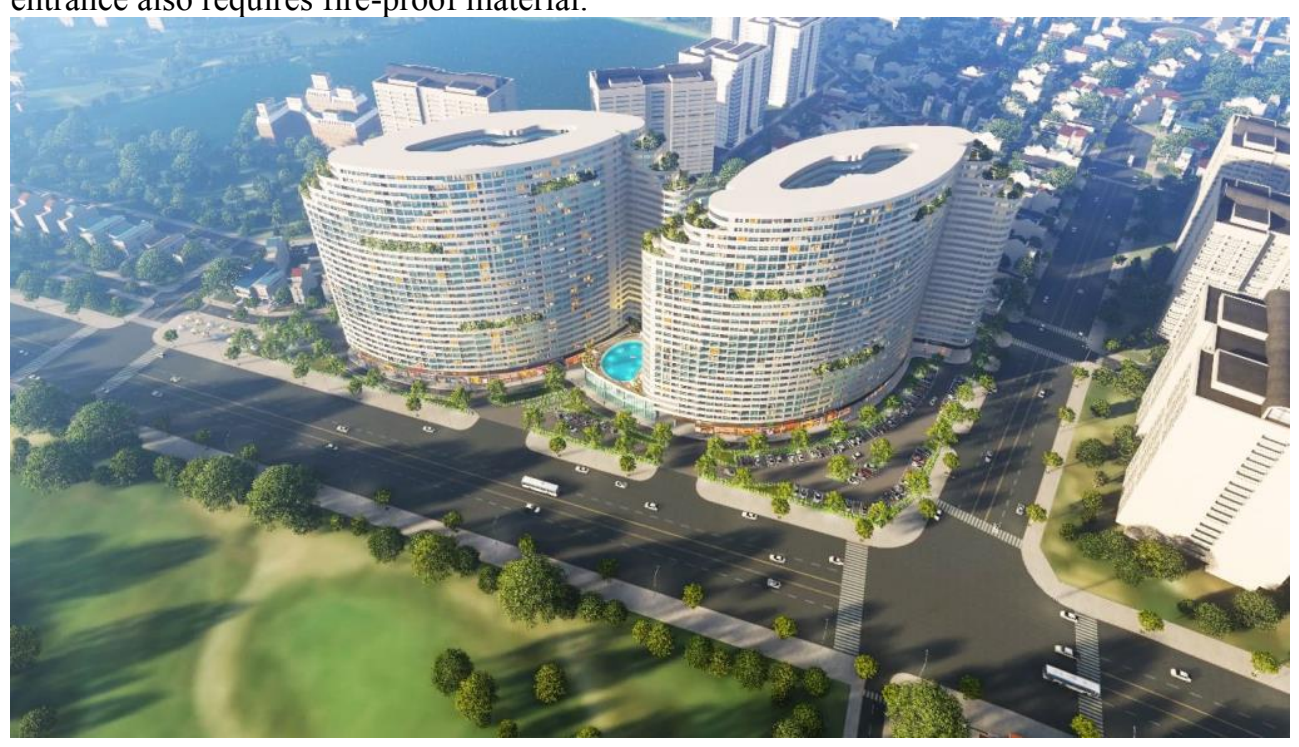

Fig.5. Limit the number of shafts in condominium

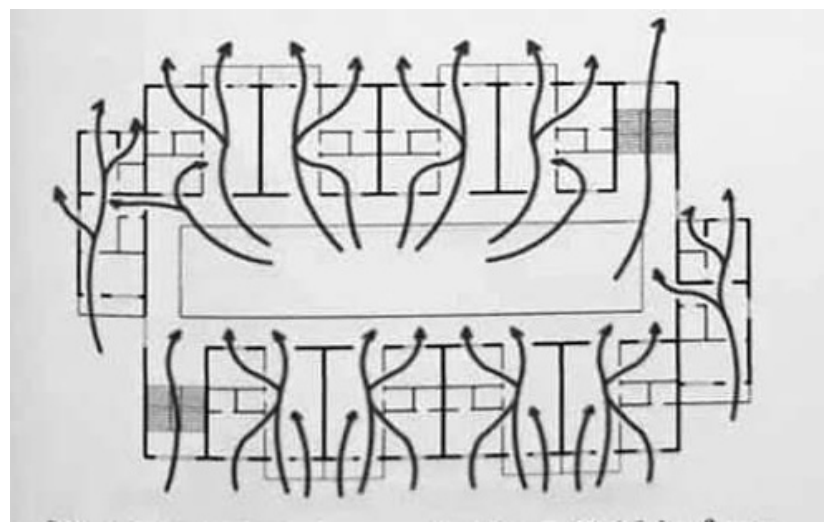

Fig. 6. Limit the number of shafts in condominium

- Limit the number of shafts in buildings that have more than 9 levels. For condominiums, shafts are not required as they can act as a path for fire, smoke and toxic gasses to spread to higher levels.

- For multi functional buildings, prioritize spaces that is capable of a large number of people such as the mall, the hall etc. on ground floor to make sure that evacuate can be done when an incident goes on.

- Garage needs to be located on the bottom level as this area has a higher risk of catching fire and producing explosions and toxic gasses which can spread vertically, making the evacuation process much harder. In the case of there is a group of residential buildings, the 
garage should be a separate unit, liking the other buildings together. The garage should not be above level 5 and 2 ground level, it is ideal to be an open area that has open air.

- The number of people in the basement levels should be as limited as possible. Do not place transformers or oil tanks in this level.

- The height outside the building has to be at least 4.25 meters so that procedures can be done by fire trucks and the fire department.

- Pathway to rooftop: should be directly from stairs or through a single floor below, or through the type 3 stairs or the fire exits outside the building.

\section{Conclusion}

Designing condominiums have many requirements and challenges and it is much different to other buildings with lower height, and the fire precautions play a great role in the safety and well-being of the residents and their properties. By researching the above requirements, it is necessary that architectural design, investor and construction companies heading towards a safety environment for the condominiums in cities in Vietnam.

\section{References}

1. QCVN 06:2010/BXD - National procedures for fire safety of households and buildings

2. Bui Manh Hung, Fire-safety and procedures in designing, building and constructing. The Ministry of Construction Publish, 84,85,86 (2003)

3. BA. Do Thanh Tung, BA. Nguyen Quoc Hoan, Model of fire-precautions for households and buildings in Viet Nam, Fire-safety and Evacuation in Viet Nam and Japanese experience. The Ministry of Construction Publish, (2018) 